\title{
Efficiency of training emotional intelligence on reducing Alexithymia syndrome in third grade male high school students
}

\author{
Morteza Amani ${ }^{1, *}$, Mahmood Goodarzi ${ }^{2}$, Hamze Ahamadian ${ }^{2}$, \\ ${ }^{1}$ M.A. in Clinical Psychology from Science and Research, Branch Kurdistan, Iran \\ ${ }^{2}$ Assistant professor, Department of Psychology, Sanandaj Branch, \\ Islamic Azad University, Sanandaj, Iran \\ *E-mail address: Amani.a303@yahoo.com
}

\begin{abstract}
In this study, the efficiency of training emotional intelligence components on reducing Alexithymia syndrome has been investigated, first using TAS_20 test and emotional intelligent test 20 high school students were selected who have received the highest scores in Alexithymia test and the lowest scores in emotional intelligence test and they were provided with intelligence components within 8 sections. Comparing the results of both control and experimental groups showed that teaching emotional components leads to reduction of Alexithymia syndrome and is significant in the level $\mathrm{F}(1,17)$ $=293 / 86, \mathrm{P}=0 / 001)$.
\end{abstract}

Keywords: Alexithymia; emotional intelligence; school students

\section{INTRODUCTION}

Alexithymia, is deficiency in describing or recognizing emotions and moods. This term was used by Signees for describing people who define emotions based on physical feelings or behavioral reactions in order to connect them with associated thoughts. In general, physical and mental health's are interdependent. Alexithymia that means inability in expressing emotions (feelings) often reminds us of the lack of feeling. These individuals have difficulty in identifying and expressing their feelings. From among the factors affecting mental health are phenomena (events) associated with interpersonal relationships. Alexithymia syndrome is of great importance here. If you don't feel well because somebody hasn't treat you appropriately or hasn't met your needs, you can cope with this situation using negotiation or social skills including establishment of relationships, while people affected by Alexithymia cannot establish any relationships in these circumstances. Alexithymia is a multifaceted construct consists of: difficulty in identifying emotions, distinguishing emotions and physical emotions associated with emotional stimulation and difficulty in expressing the feelings to someone, limited imagination ability which is defined based on deficient imagination, objective cognitive styles (non-visual) and practical and reality-based or externally oriented thinking. People affected by Alexithymia extend normal physical emotions, and they misinterpret physical symptoms of emotional stimulation, emotional distress through physical complaints and they are looking for physical treatments. Physical symptoms, anxious and insomnia and Social dysfunction and 
depression and public health are reduced due to increasing Alexithymia. People affected by Alexithymia have diffuse feelings and these feelings are associated with physiological stimulation. But because of difficulty in distinguishing, expressing and regulating emotions, stimulation remains active and is not removed and this lead to disorder in automatic nerves system and immune system. Alexithymia is likely associated indirectly with stimulating behaviors such as drug abuse, malnutrition, sedentary lifestyle, insomnia, and not following medication regime (Besharat, 2007). From 1940 to 1970, other therapists have reported similar results in patients affected by Somatoform disorders, that have problems such as inflammatorybowel disease, malnutrition, Post-traumatic stress and drug abuse (Tylor and Bagbi, 2004). Now, one of the strongest measures to determine alexithymia is 20-point Toronto (20TAS-) test that measures three dimensions: difficulty in identifying emotions, difficulty in expressing emotions and externally oriented thinking. There is enough evidence that there is a significant relationship between alexithymia and low emotional intelligence and being opening to experience (Tylor and Bagbi, 2004; Tylor et al,1992).

\section{1. Literature review}

Shahgholian et al (2007), in their study have investigated the relationship between emotional intelligence and religious orientation with mental health in students. The results show that individual's competence in controlling their mood can be useful. Those who get high scores can better perceive the reasons of the existing relationship in their emotional experiences. This contributes to individual ability to precisely understand why in different situations, certain emotions emerge. Understanding the situation leads to emotional analyzing ability and in turn better understanding of the environment. The result is efficient emotional regulation and development of mental health and well-being.

The results of the study by Besharat (2007) indicate that participants' grades in the scale of efficiency in expressing emotions with emotional intelligence and psychological well-being show significant correlation. Correlation coefficient between subscales of Alexithymia and the above variables is significant. Correlation coefficient between subscales of efficiency in expressing emotions and the above variables is significant. The results of confirmatory factor analysis 16 also have acknowledged the three factors of difficulty in identifying emotions, difficulty in expressing emotions and externally oriented thinking in the pertain version (Besharat, 2007).

\section{METHOD}

The study has investigated the efficiency of training emotional intelligence on reducing Alexithymia syndrome in male students through single variable covariance analysis( ANCOVA) and also its efficiency on three subscales of Alexithymia (difficulty in identifying emotions, difficulty in expressing emotions and externally oriented thinking) through multi variables covariance analysis.

Participants include all the third grade (year) high school students of Ghorveh in 20122013 that according to the report by Ministry of Education are 453 students. 


\section{1. Sampling}

Using available sampling method, 20 students who got the lowest score in emotional intelligence test and the highest score in (TAS-20) test were selected and they were randomly assigned to two groups: control group and experimental group.

\section{2. Participants}

Participants include 20 third- grade (year) high school students that were randomly 1 assigned to control group $(\mathrm{n}=10)$ and experimental group $(\mathrm{n}=10)$. The first Tool, is the emotional intelligence test including 90 questions that investigate 5 important arena of intrapersonal competence, interpersonal competence, adaptive competence, psychological pressure control, and general state (mood) through 15 subscales: 1- emotional consciousness, 2self-esteem, self-respect, self-actualization, autonomy, sympathy, responsibility, interpersonal relationship, reality test (realism), flexibility, problem solving, bearing pressure, controlling impulse, optimism, happiness; responses have been regulated on a 5-poin scale in the Likert spectrum (strongly agree, agree, partially agree, disagree, strongly disagree).

The second Tool is Toronto Alexithymia 20 (Begbi et al, 1992). This questionnaire is a 20-question questionnaire and three subscales (ie., difficulty in identifying emotions, difficulty in expressing emotions, and externally oriented thinking) have been investigated in Likert 5point spectrum ranged from point 1 (strongly disagree) to point5(strongly agree). Questions $(1,3,5,8,11,17,19)$ determine difficulty in identifying emotions, questions $(2,6,9,16,20)$ difficulty in expressing emotions and questions $(47,10,12,13,14,15,18)$ determine externally oriented thinking. A total score also is determined for measuring inability in expressing emotions through summing up the tree subscales. Psychological properties of TorontoAlexithymiaScale-20 have been confirmed in different studies (Taylor et al, 1992 ; Tylor and begby, 2004).

\section{FINDINGS}

First, Table 1 shows the descriptive results of the scores obtained from evaluating emotional intelligence and Alexithymia syndrome and its subscales. As Table 1 show, the mean score of emotional intelligence pretest of the control group is 251.30 and that of the posttest is 261. But the mean score of the emotional intelligence posttest score in experimental group showed much more increase compared to the pretest. Thus the mean score increased to 90.9 and changed from $269 / 60$ to $360 / 50$. The mean score of difficulty in identifying emotions pretest of control group is 24.40 and 23.50 in posttest.

The mean score of difficulty in identifying emotions post test of the experimental group decreased about 6.30 and changed from 25.20 to 18.90 . The mean score of difficulty in expressing emotions (feelings) pretest of control group is 17.45 and is 17.75 in that of post test. As it can be seen, the mean score of this variable in the post test of the experimental group has been decreased compared to the pretest. The mean score in the posttest has been reduced about 3.90 and changed from 17 to 13.10 . 
Table 1. Mean and standard deviation of emotional intelligence and Alexithymia syndrome.

\begin{tabular}{|c|c|c|c|c|}
\hline \multirow[b]{2}{*}{ Group } & \multicolumn{2}{|c|}{ Pretest } & \multicolumn{2}{|c|}{ Post test } \\
\hline & M & $\mathrm{Sd}$ & M & $\mathrm{Sd}$ \\
\hline Emotional intelligence & 251.30 & 27.54 & 261 & 24.95 \\
\hline $\begin{array}{l}\text { Difficulty in identifying } \\
\text { emotions }\end{array}$ & 24.40 & 3.09 & 23.50 & 1.96 \\
\hline $\begin{array}{c}\text { Difficulty in expressing } \\
\text { emotions }\end{array}$ & 18.20 & 2.44 & 18.50 & 2.17 \\
\hline Externally oriented thinking & 27.10 & 2.42 & 26.80 & 2.78 \\
\hline Alexithymia syndrome & 69.70 & 2.83 & 69.30 & 3.49 \\
\hline Emotional intelligence & 269.60 & 5.79 & 360.50 & 9.86 \\
\hline $\begin{array}{l}\text { Difficulty in identifying } \\
\text { emotions }\end{array}$ & 25.20 & 2.26 & 18.90 & 2.81 \\
\hline $\begin{array}{l}\text { Difficulty in expressing } \\
\text { emotions }\end{array}$ & 17 & 2.06 & 13.10 & 3.28 \\
\hline Externally oriented thinking & 29.10 & 3.99 & 17.10 & 2.33 \\
\hline Alexithymia syndrome & 71.30 & 3.59 & 49.10 & 1.66 \\
\hline
\end{tabular}

The mean score of externally oriented thinking was 27.10 in the pretest of control group and it was 26.80 in the post test. But the mean score of externally oriented thinking in the posttest of the experimental group decreased compared to pretest. The mean score in the posttest decreased about 12 scores and it changed from 29.10 to 17.10.

Finally, the mean of the total score alexithymia syndrome in pretest of the control group was 69.70 was 69.30 in post test. As the table1 shows, the total mean scores of alexithymia syndrome in post test of the experimental group decreased compared to the pretest. The mean of these scores decreased about 22.2 in post test and changed from 71.30 to 49.10 .

In order to realize the significant differences, first, the results of one-variable covariance analysis have been represented on the total scores of alexithymia syndrome of the students in Table 2. 
Table 2. The results of covariance analysis on the total score of alexithymia syndrome.

\begin{tabular}{|c|c|c|c|c|c|c|}
\hline $\begin{array}{c}\text { Significance } \\
\text { level }\end{array}$ & $\begin{array}{c}\text { Freedom } \\
\text { degree }\end{array}$ & F number & $\begin{array}{c}\text { Standard } \\
\text { of } \\
\text { deviation }\end{array}$ & $\begin{array}{c}\text { Adjusted } \\
\text { average }\end{array}$ & number & group \\
\hline 0.001 & 1,17 & 293.86 & 0.84 & 69.55 & 10 & control \\
\hline & & & 0.84 & 48.85 & 10 & experiment \\
\hline
\end{tabular}

Data on the table show that the adjusted mean of the total score of alexithymia syndrome (the mean in which the effect of the pretest has been controlled in it) among the students of the controlled group was 69.55 but it was 20.7 among the students of the experimental group. The difference between the total mean scores of alexithymia syndrome between the two groups was 16.70. Based on the results of the covariance analysis in the table the F value is 293.86 and the significant level with degree of freedom of 1 and 17 was below $0.05(F(1,17)=293 / 86 ; P=$ 0.001). Thus the difference in the mean scores of alexithymia syndrome between the students of control group and experimental group was significant and it can be said with $95 \%$ of reliability that training emotional components reduces alexithymia syndrome significantly in male students.

Table 3 shows the results of multivariable covariance in studying significant differences between the mean scores of subscales of alexithymia syndrome among male students of both control and experimental group.

Table 3. The results of multivariable-tests on the scores of subscales of alexithymia syndrome.

\begin{tabular}{|c|c|c|c|c|c|}
\hline Effects & Value & F value & $\begin{array}{c}\text { Hypothesis } \\
\text { degree of } \\
\text { freedom }\end{array}$ & $\begin{array}{c}\text { Degree of } \\
\text { Freedom } \\
\text { fault }\end{array}$ & Significant \\
\hline EffectPillaee & 0.94 & 63.97 & 3 & 13 & 0.001 \\
\hline WilksLambda & 0.06 & 63.97 & 3 & 13 & 0.001 \\
\hline Hotellingeffect & 14.76 & 63.97 & 3 & 13 & 0.001 \\
\hline Largestroot & 14.76 & 63.97 & 3 & 13 & 0.001 \\
\hline
\end{tabular}

As can be seen in Table 3, WilksLambda value is 0.06 and F value is 63.97. Significant with degree of Freedom 3 and 13 was below 0.05. $(\mathrm{P}<0 / 05)$. This fact indicates that there is a significant difference among male students of both control group and experimental group at least in one of the symptoms of alexithymia syndrome.

To realize that in which aspects of alexithymia the significant difference can be seen among the male students of the two groups, the three analyses of single variable covariance has been conducted in the context of multi variables - covariance. The results are shown in Table 4: 
Table 4. The results of the three analyses of single variable variance in the context of multivariances on the scores of subscales of alexithymia syndrome.

\begin{tabular}{|c|c|c|c|c|c|c|c|}
\hline $\begin{array}{l}\text { Alexithymia } \\
\text { syndrome }\end{array}$ & group & number & $\begin{array}{l}\text { Adjusted } \\
\text { average }\end{array}$ & $\begin{array}{c}\text { Standard } \\
\text { of } \\
\text { deviation }\end{array}$ & $\begin{array}{c}F \\
\text { value }\end{array}$ & $\begin{array}{c}\text { Degree } \\
\text { of } \\
\text { freedom }\end{array}$ & Significance \\
\hline \multirow{2}{*}{$\begin{array}{c}\text { Difficulty in } \\
\text { identifying } \\
\text { feelings } \\
\text { (emotions) }\end{array}$} & control & 10 & 23.50 & 0.88 & \multirow{2}{*}{12.26} & \multirow{2}{*}{1,15} & \multirow{2}{*}{0.003} \\
\hline & experimental & 10 & 18.90 & 0.88 & & & \\
\hline \multirow{2}{*}{$\begin{array}{c}\text { Difficulty in } \\
\text { expressing } \\
\text { emotions } \\
\text { (feelings) }\end{array}$} & control & 10 & 18.39 & 0.94 & \multirow{2}{*}{13.78} & \multirow{2}{*}{1,15} & \multirow{2}{*}{0.002} \\
\hline & experimental & 10 & 3.20 & 0.94 & & & \\
\hline \multirow{2}{*}{$\begin{array}{c}\text { Externally } \\
\text { oriented } \\
\text { thinking }\end{array}$} & control & 10 & 27.24 & 0.81 & \multirow{2}{*}{75.87} & \multirow{2}{*}{1,15} & \multirow{2}{*}{0.001} \\
\hline & experimental & 10 & 16.66 & 0.81 & & & \\
\hline
\end{tabular}

Because three separate analyses have been conducted, Ben Ferroni adjustment should be used. This means that the alpha $(\alpha)$ level of 0.05 be divided by the number of analyses. So, we should divide 0.05 by 3 and the significance of 0.016 should be used for each analysis. Based on the adjusted mean in table 4 , it can be observed that the mean scores of difficulty in identifying emotions among the students in control group is 23.50 but that of the experimental group is 18. 90. The mean score of difference between the two groups is 4.60.

Based on the results of covariance analysis in the above table, F value is 12.26 and the significant with freedom degree 1 and 15 was below $0.17(F(1,15)=12.26, p=0.003)$. So the difference in terms of the mean score of difficulty in identifying emotions (feelings) among the students of both control and experimental group is significant and it can be said with $95 \%$ of reliability that training emotional intelligence reduced difficulty in identifying emotions (feelings) among male students. As the table 4 shows, the adjusted mean scores of difficulty in expressing emotions in control group is 18.39 but that of experimental group is 13.20.

The difference in mean score between the two groups is 4.60. Based on the results of covariance analysis in the above table, $\mathrm{F}$ equals 13.78 and significance level with freedom degree of 1 and 15 is below 0.017. $(F(1,15)=13.78, P=0.002)$. So the difference in mean score of difficulty in expressing emotions among the control and experimental group is significant and it can be said with $95 \%$ of reliability that training emotional intelligence components significantly reduced difficulty in expressing emotions in male students. Finally as the table 4 shows, the adjusted mean score of objective thinking in control group is 27.24 but that of experimental group is 16.66 . The difference in mean score of the two groups is 10.58. Based on the results of covariance analysis in the above table, $F$ value is 75.87 and the significant with freedom degree 1 and 15 is below $0.017(\mathrm{~F}(1,15)=75.78, \mathrm{P} 0.002)$. So the difference in average score of externally oriented thinking among the control and experimental group is significant and it can be said with $95 \%$ of reliability that training emotional intelligence components significantly reduced externally oriented thinking among male students. So the research hypothesis is confirmed. 


\section{CONCLUSION}

As statistical analysis show, the total mean score of alexithymia syndrome and its subscales decreased in posttest of experimental group compared to control group. While the mean score of pretest and posttest in control group has not showed any significant changes. Findings of covariance analysis show that training emotional intelligence components has led significantly to reducing alexithymia syndrome in male students. Also, the adjusted mean score in all the three subscales of alexithymia syndrome (i.e., difficulty in identifying emotions (feelings), difficulty in expressing feelings and externally oriented thinking) was significantly higher in male students of experimental group compared to male students in control group. Thus it is clear that training emotional intelligence components in experimental group significantly reduced difficulty in identifying emotions, difficulty in expressing feelings and externally oriented thinking in male students. Finally, Ata-square values show that the effect of efficiency of training emotional intelligence components in male students led to reducing objective thinking more than difficulty in identifying and expressing emotions (Tabachnic and Fidell, 2007).

Considering the fact that the study investigated the effect of emotional intelligence components as an independent variable on decreasing alexithymia syndrome, when the components have been exposed to intervention trial (here emotional intelligence are analyzed as dependent variable)the results show that intervention trial increase emotional intelligence, considering overlapping of emotional intelligence components indicates that the more emotional intelligence, the less problem in representing emotions. The result is consisted with that of.

\section{References}

[1] Besharat M. A., Psychological Reports 101 (2007) 209 -220.

[2] Taylor G. J., Bagby M., Psychotherapy and Psychosomatics 73 (2004) 68-77.

[3] Tabachnic, B. G., Fidell L. S., Using multivariate statistics, 2007.

[4] Taylor, G. J., Parker, J. D. A. Bagby, M., Acklin, M. W., Journal of Psychosomatic Research 36 (1992) 417-424.

[5] Shahgholian M., Moradi A. S., Kafi M., Iranian Journal of Psychiatry and Clinical Psychology 3(3) (2007) 21-32. 